\title{
Comparison of Three Fractionation Schedules in Radiotherapy for Early Glottic Squamous Cell Carcinoma
}

\author{
GEN SUZUKI $^{1}$, HIDEYA YAMAZAKI ${ }^{1}$, NORIHIRO AIBE ${ }^{1}$, KOJI MASUI $^{1}$, DAISUKE SHIMIZU ${ }^{1}$, \\ TAKUYA KIMOTO $^{1}$, TAKESHI NISHIMURA ${ }^{1}$, KANAKO KAWABATA ${ }^{1}$, SHINSUKE NAGASAWA ${ }^{1}$, \\ KAZUTAKA MACHIDA $^{1}$, YUKI YOSHINO ${ }^{1}$, SHO WATANABE ${ }^{1}$, \\ YOICHIRO SUGIYAMA ${ }^{2}$, AKIHITO ARAI ${ }^{2}$, SHIGERU HIRANO ${ }^{2}$ and KEI YAMADA ${ }^{1}$ \\ ${ }^{1}$ Department of Radiology, Kyoto Prefectural University Graduate School of Medical Science, Kyoto, Japan; \\ ${ }^{2}$ Department of Otolaryngology-Head and Neck Surgery, \\ Kyoto Prefectural University Graduate School of Medical Science, Kyoto, Japan
}

\begin{abstract}
Background/Aim: Radiotherapy is widely accepted as the treatment of choice for early glottic squamous cell carcinoma (EGSCC), although it varies greatly with respect to dose, dose per fraction, and treatment techniques. The study aim was to evaluate the use of accelerated fractionation strategy (AFS) for EGSCC in standard clinical practice. Patients and Methods: Patients treated with definitive radiotherapy for EGSCC between 2008 and 2019 were retrospectively identified and received either conventional fractionation, hypofractionation, or hyperfractionation. Results: One hundred six patients were analyzed, and 19, 71, and 16 patients underwent conventional fractionation, hypofractionation, and hyperfractionation, respectively. The median follow-up was 56 months. The 5-year local control and overall survival rates were $79 \%$ and $83 \%$; $78 \%$ and $79 \%$; and $87 \%$ and $77 \%$, respectively, and no significant difference was observed between the fractionation schedules. Conclusion: Our findings confirmed the utility of AFS in standard clinical practice and support its use for patients with EGSCC.
\end{abstract}

One duty of a multidisciplinary team is to evaluate and offer patients the best treatment options based on evidence of longterm functional outcomes after curatively intended therapy for

This article is freely accessible online.

Correspondence to: Gen Suzuki, MD, Department of Radiology, Kyoto Prefectural University of Medicine, 465 Kajiicho Kawaramachi Hirokoji, Kamigyo-ku, Kyoto 602-8566 Japan. Tel: +81 752515618, Fax: +81 752515840, e-mail: gensuzu@koto.kpum.ac.jp

Key Words: Glottic cancer, radiation, hypofractionation, hyperfractionation, late-course accelerated hyperfractionation, altered fractionation. laryngeal cancer (1). Treatment options for T1-2N0 early glottic squamous cell carcinoma (EGSCC) include radiotherapy (RT), cordectomy, and laser microsurgery. Patients with EGSCC have shown excellent local control (LC) and survival rates, with voice quality preservation and low toxicity levels after undergoing RT (2); thus, RT is the preferred treatment option among these patients $(3,4)$. Although RT is widely accepted as the treatment of choice for early glottic cancer, it varies greatly with respect to dose, dose per fraction, and treatment techniques (5-9). The accelerated repopulation of surviving clonogenic tumor cells during the RT period, known to be a key factor determining the LC rate in head and neck cancer, has also been observed in patients with early glottic carcinomas. The LC rate of accelerated RT using an accelerated fractionation strategy (AFS) that reduces the overall treatment time (OTT) by either increasing the number of fractions per day (hyperfractionation) or increasing the dose per fraction (hypofractionation) has been reported to be superior to that of conventional fractionation $(\mathrm{CF})$ with a 1.8-2.0 Gy daily schedule (10-13).

To our knowledge, there are no published studies that have compared the treatment results of $\mathrm{CF}$, hypofractionation, and hyperfractionation as definitive RT for EGSCC. The purpose of this study was to evaluate the use of AFS for EGSCC in standard clinical practice.

\section{Patients and Methods}

Patients. We retrospectively reviewed the records of consecutive patients with T1-2NOM0 EGSCC who received definitive RT at our Institution between January 2008 and December 2019. With the aid of microlaryngoscopy, biopsy specimens were obtained from all patients, histopathologically examined, and proven to be squamous cell carcinoma. The stage of cancer was determined according to the seventh edition of the American Joint Committee on Cancer (14). This study was approved by the Institutional Review Board of the Kyoto Prefectural University of Medicine (approval number 
ERB-C-1727). Written informed consent was obtained from each patient prior to treatment for publication of this article and any accompanying images.

Radiotherapy. The patients in a supine position were treated with fixation using thermoplastic masks. Three-dimensional conformal RT was administered by using two opposite parallel fields with or without a paired wedge and by modulating the field weight or performing dose normalization to improve the target coverage. Computed tomography-based radiation planning was performed with a slice thickness of $2 \mathrm{~mm}$. RT was delivered by 4- or 6-MV linear accelerators. Gross tumor volumes were measured to include $\geq 2$-cm margins in all directions. Elective neck RT was not used for any of the patients. The minimum field size was $5 \times 5 \mathrm{~cm}$, centered over the mid-thyroid cartilage. The dose was prescribed at the intersection of beams in the mid-plane. Patients in the CF and hypofractionation groups received 60-70 Gy in 2.0-Gy daily fractions and 63-65.25 Gy in 2.25-Gy daily fractions, respectively, according to each patient's $\mathrm{T}$ stage. The patients in the hyperfractionation group received RT in the form of late-course acceleration to a total dose of $60 \mathrm{~Gy}$ in 45 fractions. In this group, RT was delivered to provide 30 Gy in 2.0-Gy daily fractions, and the remaining $30 \mathrm{~Gy}$ in 20 fractions was delivered as 1.5 -Gy twicedaily fractions. Twice-daily treatments were delivered with a minimum inter-fraction interval of 6 hours.

Evaluation of treatment outcome and toxicity. The patients were regularly evaluated by performing laryngoscopy and physical examinations during the treatment period and at routine follow-up visits. During the treatment, patients were examined at least weekly. Once treatment ended, all patients were followed up every 1 to 2 months during the first 2 years and every 3 to 4 months thereafter. Acute and chronic treatment toxicities were documented according to the Common Terminology Criteria for Adverse Events version 4.0 (15). Follow-up data were obtained from the electronic medical records.

Statistical analysis. Overall survival (OS) was measured from the date of treatment initiation to the date of the last follow-up or death from any cause. Disease-free survival (DFS) was measured from treatment initiation to the first observation of any recurrence. LC was measured from treatment initiation to the first local recurrence. Laryngectomy-free survival was measured from treatment initiation to laryngectomy or death from any cause. OS, DFS, LC, and laryngectomy-free survival were calculated by using the KaplanMeier method. In the univariate analyses, differences between groups were estimated by performing the log-rank test.

All statistical analyses were performed in EZR software (Saitama Medical Center, Jichi Medical University, Saitama, Japan), a graphical user interface for R (The R Foundation for Statistical Computing, Vienna, Austria, version 2.13.0); EZR is a modified version of $\mathrm{R}$ commander (version 1.6-3) that was designed to add statistical functions frequently used in biostatistics (16). In all analyses, values of $p<0.05$ were considered to indicate a statistically significant difference.

\section{Results}

Patient characteristics. One hundred and seven patients were enrolled during the study period; of these, one patient in the hypofractionation group was excluded because he refused

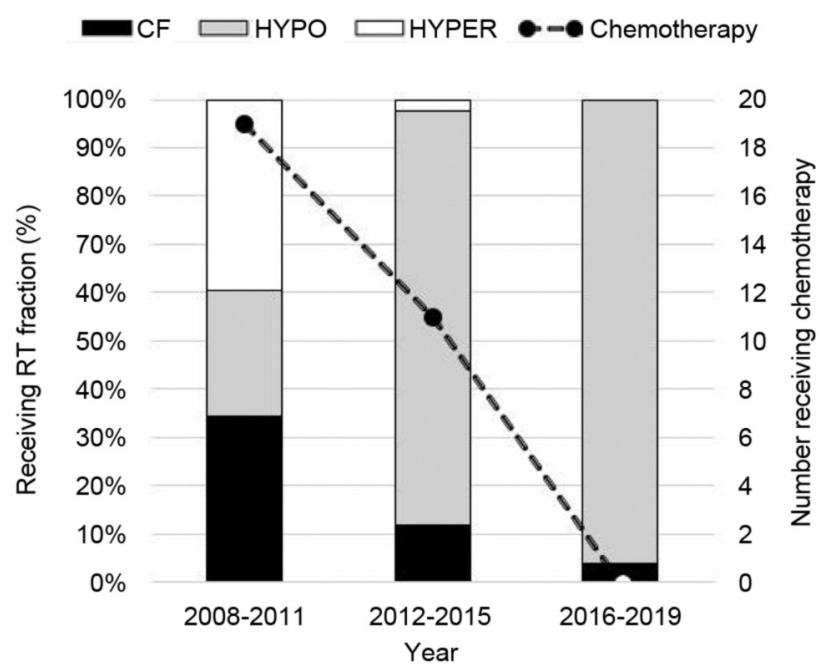

Figure 1. Patterns of fractionation over time. CF: Conventional fractionation; HYPO: hypofractionation; HYPER: hyperfractionation; $R T$ : radiotherapy.

continuation of RT for personal reasons that were not related to treatment toxicity. Therefore, we evaluated 106 patients in total. There were 94 men and 12 women; the male-to-female ratio was 9:1. The median patient age was 70 years (range $=47-$ 88 years). Forty-eight $(45 \%)$ and $58(55 \%)$ patients had T1 and T2 tumors, respectively. Most patients had a good Eastern Cooperative Oncology Group performance status (0-1). There were 19,71 , and 16 patients in the $\mathrm{CF}$, hypofractionation, and hyperfractionation groups, respectively. The median duration of treatment was 36 days (range $=33-40$ days) in the hyperfractionation arm, 41 days (range $=38-55$ days) in the hypofractionation arm, and 47 days (range $=42-53$ days) in the CF arm. All patients completed the planned RT schedule. Chemotherapy was concurrently administered with RT in 30 patients ( 28 in those with T2 tumors and two in those with T1 tumors). The most common regimen was weekly carboplatin, which was used in 23 out of 30 patients. The remaining seven received a triweekly regimen of cisplatin. Chemotherapy usage gradually decreased, and no patients have received it since 2016 (Figure 1). Analysis of fractionation with year as the period variable demonstrated significant declines from 2008-2011 to 2016-2019 in the use of both CF (from 34\% to $4 \%$ ) and hyperfractionation (from $37 \%$ to $0 \%$ ), an overall period when hypofractionation was increasingly used (from $26 \%$ to $96 \%$ ) (Figure 1). Table I summarizes the clinical characteristics of the 106 patients in the study population associated with the three fractionation schedules.

Follow-up and survival. The overall median follow-up duration was 56.3 months (range=3-130 months) from the initiation of RT. Among the 106 patients, five died of glottic 
Table I. Clinical characteristics.

\begin{tabular}{|c|c|c|c|}
\hline \multirow[t]{2}{*}{ Characteristic } & \multicolumn{3}{|c|}{ Group, n (\%) } \\
\hline & $\begin{array}{c}\mathrm{CF} \\
(\mathrm{n}=19)\end{array}$ & $\begin{array}{l}\text { Hypofractionation } \\
\qquad(\mathrm{n}=71)\end{array}$ & $\begin{array}{l}\text { Hyperfractionation } \\
\qquad(\mathrm{n}=16)\end{array}$ \\
\hline \multicolumn{4}{|c|}{$\begin{array}{l}\text { Follow-up period, } \\
\text { months }\end{array}$} \\
\hline Median (range) & $60(16-122)$ & $41(3-107)$ & $101(3-130)$ \\
\hline \multicolumn{4}{|c|}{ Age, years } \\
\hline Median (range) & $71(47-88)$ & $70(52-86)$ & $64(52-86)$ \\
\hline \multicolumn{4}{|l|}{ Age, n (\%) } \\
\hline$\leq 69$ Years & $8(42 \%)$ & $32(45 \%)$ & $12(75 \%)$ \\
\hline >69 Years & $11(58 \%)$ & $39(55 \%)$ & $4(25 \%)$ \\
\hline \multicolumn{4}{|l|}{ Gender, n (\%) } \\
\hline Male & $15(79 \%)$ & $65(92 \%)$ & $14(88 \%)$ \\
\hline Female & $4(21 \%)$ & $6(8 \%)$ & $2(12 \%)$ \\
\hline \multicolumn{4}{|l|}{ PS, n (\%) } \\
\hline 0 & $18(95 \%)$ & $67(94 \%)$ & $15(97 \%)$ \\
\hline 1 or 2 & $1(5 \%)$ & $4(6 \%)$ & $1(3 \%)$ \\
\hline \multicolumn{4}{|l|}{ Hemoglobin, n (\%) } \\
\hline$\leq 12.9 \mathrm{~g} / \mathrm{dl}$ & $7(37 \%)$ & $19(27 \%)$ & $7(44 \%)$ \\
\hline$>12.9 \mathrm{~g} / \mathrm{dl}$ & $12(63 \%)$ & $52(73 \%)$ & $9(56 \%)$ \\
\hline $\mathrm{T} 1$ & $7(37 \%)$ & $35(49 \%)$ & $6(38 \%)$ \\
\hline $\mathrm{T} 2$ & $12(63 \%)$ & $36(51 \%)$ & $10(62 \%)$ \\
\hline \multicolumn{4}{|l|}{ CCRT, n (\%) } \\
\hline Yes & $10(53 \%)$ & $10(16 \%)$ & $10(62 \%)$ \\
\hline No & $9(47 \%)$ & $61(84 \%)$ & $6(38 \%)$ \\
\hline
\end{tabular}

CCRT: Concurrent chemotherapy; PS: performance status; CF: conventional fractionation.

cancer and 14 died of other diseases, especially second primary cancer. The 2- and 5-year OS rates determined by the Kaplan-Meier method for all patients were $95.8 \%$ and $86.3 \%$, respectively. Figure 2 shows a comparison of the OS rates between treatment groups. The 5-year OS rates in the $\mathrm{CF}$, hypofractionation, and hyperfractionation groups were $83 \%, 79 \%$, and $77 \%$, respectively, and no significant difference was observed between treatment groups $(p=0.504)$. Local recurrence was observed in a total of 18 patients, with four in the CF group, 12 in the hypofractionation group, and two in the hyperfractionation group. The median time to local recurrence was 8.6 months (range=3.6-36.2 months) after RT. Regional lymph node recurrence and distant metastases were observed in one and two patients, respectively. The 2- and 5-year DFS rates for all patients were $81.5 \%$ and $78.7 \%$, respectively. After identification of local recurrences, 17 out of 18 patients underwent salvage surgery and one refused any salvage treatment. Eventually, seven patients underwent total laryngectomy. The 2- and 5-year LC rates for patients overall were $83.2 \%$, and $80.4 \%$, respectively. The 5 -year LC rates in the $\mathrm{CF}$, hypofractionation, and hyperfractionation groups were $79 \%, 78 \%$, and $87 \%$, respectively, and no significant

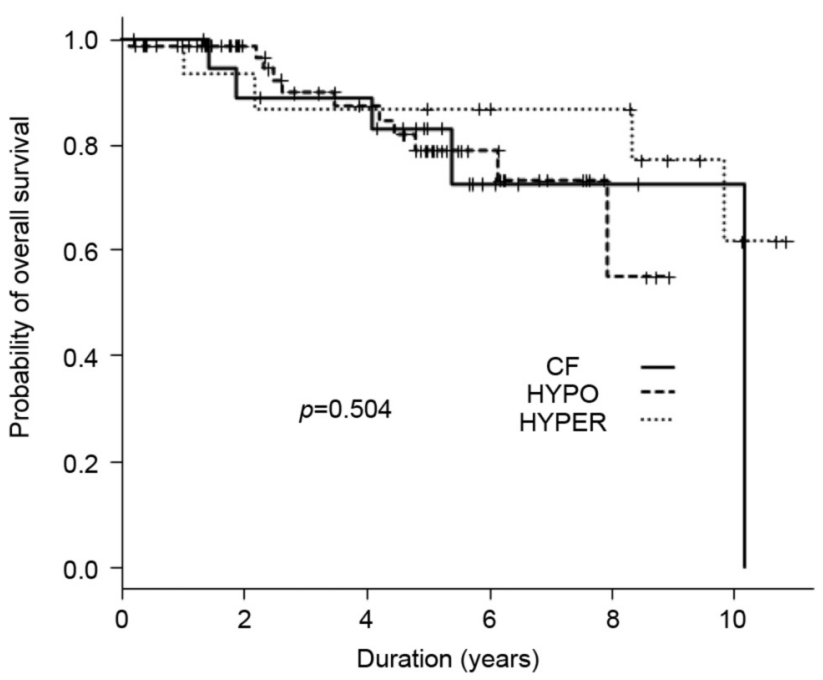

Figure 2. Overall survival curve by treatment group. No significant differences among the three fractionation schedules were observed. $C F$ : Conventional fractionation; HYPO: hypofractionation; HYPER: hyperfractionation.

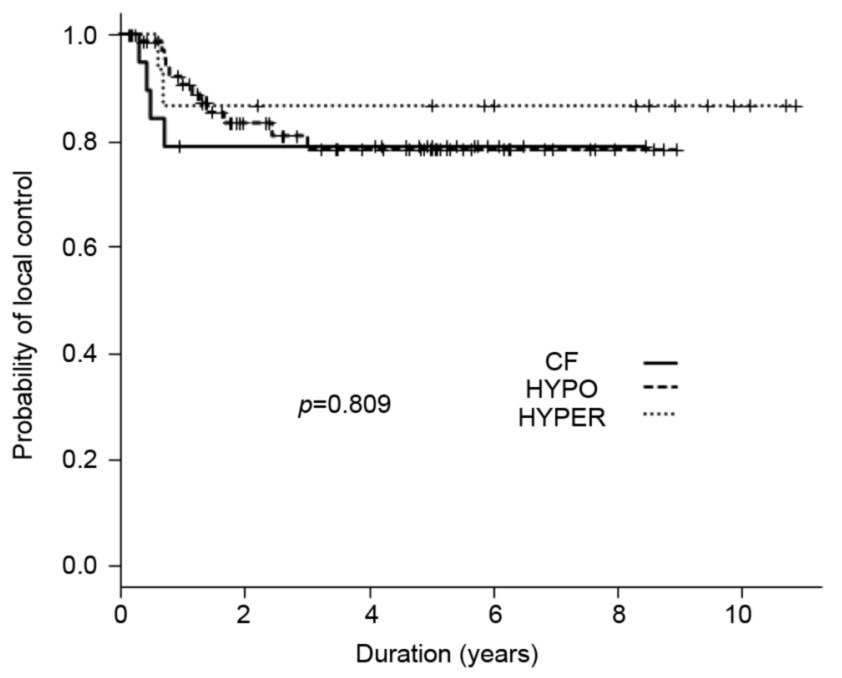

Figure 3. Local control curve by treatment group. No significant differences among the three fractionation schedules were observed. $C F$ : Conventional fractionation; HYPO: hypofractionation; HYPER: hyperfractionation.

difference was observed between the treatment groups ( $p=0.809$, Figure 3 ). For the entire group, the 5 -year total laryngectomy-free survival rate was $70.4 \%$ (CF, 73.3\%; hypofractionation, $67.2 \%$; hyperfractionation, $66.3 \%$; differences not significant). Table II presents the results of the univariate analysis for OS and LC. Age ( $\leq 69 v s .>69$ years), clinical T stage (T1 vs. T2), hemoglobin level ( $\leq 12.9$ 
Table II. Univariate analysis for overall survival (OS) and local control (LC) rates.

\begin{tabular}{|c|c|c|c|c|c|c|}
\hline & & $\mathrm{n}$ & 5 -Year OS (\%) & $p$-Value & 5-Year LC (\%) & $p$-Value \\
\hline \multirow[t]{2}{*}{ Age } & $\leq 69$ Years & 52 & 87.8 & 0.084 & 80.3 & 0.905 \\
\hline & $>69$ Years & 54 & 77.2 & & 80.3 & \\
\hline \multirow[t]{2}{*}{ Sex } & Male & 94 & 81 & 0.176 & 79 & 0.425 \\
\hline & Female & 12 & 100 & & 91.7 & \\
\hline \multirow[t]{2}{*}{ PS } & $0^{\prime}$ & 100 & 80.6 & 0.541 & 80.6 & 0.823 \\
\hline & 1 or 2 & 6 & 75 & & 75 & \\
\hline \multirow[t]{2}{*}{ Hemoglobin } & $\leq 12.9 \mathrm{~g} / \mathrm{dl}$ & 33 & 81.2 & 0.835 & 75.6 & 0.436 \\
\hline & $>12.9 \mathrm{~g} / \mathrm{dl}$ & 73 & 83.8 & & 83.4 & \\
\hline \multirow[t]{2}{*}{ Clinical T-stage } & $\mathrm{T} 1$ & 48 & 86.2 & 0.309 & 82.6 & 0.439 \\
\hline & $\mathrm{T} 2$ & 58 & 79.7 & & 79 & \\
\hline \multirow[t]{2}{*}{ CCRT } & Yes & 30 & 88.7 & 0.535 & 81.8 & 0.849 \\
\hline & No & 76 & 79.7 & & 79.5 & \\
\hline \multirow[t]{3}{*}{ RT } & $\mathrm{CF}$ & 19 & 83 & 0.504 & 78.9 & 0.809 \\
\hline & Hypofractionation & 71 & 80.6 & & 78.3 & \\
\hline & Hyperfractionation & 16 & 86.7 & & 86.7 & \\
\hline
\end{tabular}

CCRT: Concurrent chemotherapy; OS: overall survival; LC: local control; PS: performance status; CF: conventional fractionation.

$v s .>12.9 \mathrm{~g} / \mathrm{dl}$ ), and concurrent chemotherapy usage (yes $v s$. no) did not affect OS and LC.

Toxicities. Most of the patients, regardless of treatment group, had grade 1 or 2 mucositis and dermatitis during the treatment. One patient in the hypofractionation group developed grade 3 laryngeal edema, which responded to antibiotics and oral steroids. Treatment interruption was not experienced in this patient. Except for this case, no severe acute/chronic toxicities of grade 3 or higher were observed.

\section{Discussion}

In our study, the 5-year LC and OS rates were $80.4 \%$ and $86.3 \%$, respectively, and we did not find significant differences among the three fractionation schedules. The rates of adverse events of grade 3 or greater in our study groups $(<1 \%$ in all patients, $1.4 \%$ of hypofractionation) were comparable or slightly lower than the reported $1-3 \%$ range $(3,12,17,18)$. To the best of our knowledge, this is the first study that has directly compared the treatment results of $\mathrm{CF}$, hypofractionation, and late-course accelerated hyperfractionation as definitive RT for EGSCC. The LC and OS rates in our study were comparable to those of recent prospective randomized studies involving hypofractionation $(11,13)$.

Prolongation of RT for head and neck cancer may worsen LC because of so-called 'accelerated tumor clonogen repopulation during RT', which leads to treatment resistance (19). Therefore, studies with intensification of AFS that reduces the OTT have been conducted either by increasing the dose per fraction (hypofractionation) or increasing the number of fractions per day (hyperfractionation). Some clinical results of definitive RT for EGSCC suggest that both hypofractionation and hyperfractionation are beneficial for LC $(6,10)$. In a systematic review and meta-analysis of 1,762 patients, the benefit of accelerated fractionation RT persisted when each type of AFS was analyzed separately (6). This finding is in accordance with a single-institution retrospective analysis of 230 patients, which indicated that hyperfractionation schedules were similarly effective in terms of LC when compared with hypofractionation regimens with $>2$ Gy per fraction (20). These findings support the idea that either AFS (hypofractionation or hyperfractionation) may have a beneficial effect on LC. In our study, we used late-course accelerated fractionation in the hyperfractionation group. Despite being a variant of accelerated fractionation, latecourse accelerated hyperfractionation is associated with minimal enhancement of acute reactions because it uses the concepts of accelerated fractionation while minimizing the volume of tissue irradiated with high doses. There are only limited data comparing late-course accelerated fractionation with other fractionation schedules of EGSCC (21). In our study, although many patients in the hyperfractionation group received chemotherapy, this fractionation schedule was found to be feasible and tolerable.

The Japanese prospective randomized trial by Yamazaki et al. that recruited 180 patients with only T1 tumors demonstrated significant LC gain with hypofractionation at $2.25 \mathrm{~Gy}$ per day compared with the CF (92\% vs. $77 \%$, $p=0.004$ ) (12). In contrast, a similar trial from Korea enrolling patients with T1 and T2 disease reported that use of the same dose per fraction led to non-significant improvement in local progression-free survival (11). A recent review by Sapienza et al. indicated that this LC benefit of AFS may not extend to T2 tumors because of the lack of a benefit in studies with predominantly T2 disease (6). In fact, a Radiation Therapy 
Oncology Group trial (\#9512) which recruited 239 patients with only T2 tumors failed to show a significant benefit of AFS (22), a finding that supported pooled study findings by Sapienza et al. In our study, more than half of the enrolled patients had T2 tumors, which may be one of the reasons why we did not find any benefits of AFS in LC.

At our Institution, the RT fractionation schedules for EGSCC have changed dramatically over the past decade. The relative benefits of hypofractionation and hyperfractionation need to be balanced against the OTT and inconvenience with which these approaches are associated. hyperfractionation has the advantage of shortening the OTT over $\mathrm{CF}$ and hypofractionation. On the other hand, the advantages of hypofractionation are not only shortened OTT but also reduced medical costs, frequency of patient visits, equipment burden, and staff labor. Consequently, hypofractionation has gained favor in recent years because this schedule is more advantageous for both patients and staff. Therefore, the use of hyperfractionation and CF at our Institution have been decreasing over the past few years (Figure 1), which is consistent with a study in the United States that showed increased use of hypofractionation for EGSCC over the years, with more than half of patients choosing it recently $(10,23)$. Moore et al. and consensus guidelines strongly recommend hypofractionation as the standard of care. The finding of significant public health cost savings by Moore et al. is an additional benefit of treatment with hypofractionation (24).

There were some limitations to our study because of its single-institution and retrospective nature. The number of patients was small and the selections of the RT options in the patients were not randomized. Additionally, a number of patients received chemotherapy concurrently with RT. Consequently, because selection bias may have occurred, care is needed in interpreting the study results. To confirm our results, it is important to continue to treat and evaluate greater numbers of patients and to report longer term follow-up data.

In conclusion, there were no significant differences in LC and OS between the three fractionation schedules. Our findings confirmed the utility of AFS in standard clinical practice and support its use for patients with EGSCC.

\section{Conflicts of Interest}

The Authors declare that they have no conflicts of interest regarding this study.

\section{Authors' Contributions}

GS designed the study, contributed to data acquisition, and prepared the article. HY performed statistical analyses and reviewed the article. GS, YS, AA, HY, NA, KM, DS, TK, TN, KK, SN, YY, SW, and $\mathrm{KM}$ contributed to data acquisition. $\mathrm{HY}, \mathrm{SH}$, and $\mathrm{KY}$ supervised the study. All Authors have read and approved the final article.

\section{References}

1 Anschuetz L, Shelan M, Dematté M, Schubert AD, Giger R and Elicin O: Long-term functional outcome after laryngeal cancer treatment. Radiat Oncol 14(1): 101, 2019. PMID: 31186027. DOI: $10.1186 / \mathrm{s} 13014-019-1299-8$

2 Lim YJ, Wu H-G, Kwon T-K, Hah JH, Sung M-W, Kim KH and Park C Il: Long-term outcome of definitive radiotherapy for early glottic cancer: Prognostic factors and patterns of local failure. Cancer Res Treat 47(4): 862-870, 2015. PMID: 25687859. DOI: $10.4143 /$ crt.2014.203

3 Mendenhall WM, Amdur RJ, Morris CG and Hinerman RW: T1T2N0 Squamous cell carcinoma of the glottic larynx treated with radiation therapy. J Clin Oncol 19(20): 4029-4036, 2001. PMID: 11600604. DOI: $10.1200 / J C O .2001 .19 .20 .4029$

4 Smee RI, Meagher NS, Williams JR, Broadley K and Bridger GP: Role of radiotherapy in early glottic carcinoma. Head Neck 32(7): 850-859, 2009. PMID: 20029987. DOI: 10.1002/hed. 21262

5 Mendenhall WM, Werning JW, Hinerman RW, Amdur RJ and Villaret DB: Management of T1-T2 glottic carcinomas. Cancer 100(9): 1786-1792, 2004. PMID: 15112257. Doi 10.1002/cncr. 20181

6 Sapienza LG, Ning MS, Taguchi S, Calsavara VF, Pellizzon AC de A, Gomes MJL, Kowalski LP and Baiocchi G: Alteredfractionation radiotherapy improves local control in early-stage glottic carcinoma: A systematic review and meta-analysis of 1762 patients. Oral Oncol 93: 8-14, 2019. PMID: 31109700. DOI: $10.1016 /$ j.oraloncology.2019.04.007

7 Ermiş E, Teo M, Dyker KE, Fosker C, Sen M and Prestwich RJD: Definitive hypofractionated radiotherapy for early glottic carcinoma: experience of 55Gy in 20 fractions. Radiat Oncol 10: 203, 2015. PMID: 26395876. DOI: 10.1186/s13014-015-0505-6

8 Korpics MC, Turchan WT, Rooney MK, Koshy M and Spiotto MT: Patterns of care and outcomes of intensity-modulated radiotherapy and $3 \mathrm{D}$ conformal radiotherapy for early-stage glottic cancer: A National Cancer Database analysis. Cancers 11(12): 1996, 2019. PMID: 31842271. DOI: 10.3390/ cancers 11121996

9 Mohamed ASR, Smith BD, Smith JB, Sevak P, Malek JS, Kanwar A, Browne T, Gunn GB, Garden AS, Frank SJ, Morrison WH, Phan J, Zafereo M, Skinner H, Lai SY, Hutcheson KA, Lewin JS, Hessel AE, Thekdi AA, Weber RS, Fuller CD and Rosenthal DI: Outcomes of carotid-sparing IMRT for T1 glottic cancer: Comparison with conventional radiation. Laryngoscope 130(1): 146-153, 2020. PMID: 30756394. DOI: 10.1002/lary. 27873

10 Stokes WA, Stumpf PK, Jones BL, Blatchford PJ, Karam SD, Lanning RM and Raben D: Patterns of fractionation for patients with T2N0M0 glottic larynx cancer undergoing definitive radiotherapy in the United States. Oral Oncol 72: 110-116, 2017. PMID: 28797446. DOI: 10.1016/j.oraloncology.2017.07.013

11 Moon SH, Cho KH, Chung EJ, Lee CG, Lee KC, Chai G-Y, Kang KM, Lee JY, Chung W-K, Park WY and Kim JH: A prospective randomized trial comparing hypofractionation with conventional fractionation radiotherapy for T1-2 glottic squamous cell carcinomas: Results of a Korean Radiation Oncology Group (KROG-0201) study. Radiother Oncol 110(1): 98-103, 2014. PMID: 24161568. DOI: 10.1016/j.radonc. 2013.09.016 
12 Yamazaki H, Nishiyama K, Tanaka E, Koizumi M and Chatani M: Radiotherapy for early glottic carcinoma (T1NOM0): Results of prospective randomized study of radiation fraction size and overall treatment time. Int J Radiat Oncol 64(1): 77-82, 2006. PMID: 16169681. DOI: 10.1016/j.ijrobp.2005.06.014

13 Kodaira T, Kagami Y, Shibata T, Shikama N, Nishimura Y, Ishikura S, Nakamura K, Saito Y, Matsumoto Y, Teshima T, Ito Y, Akimoto T, Nakata K, Toshiyasu T, Nakagawa K, Nagata Y, Nishimura T, Uno T, Kataoka M, Yorozu A and Hiraoka M: Results of a multiinstitutional, randomized, non-inferiority, phase III trial of accelerated fractionation versus standard fractionation in radiation therapy for T1-2N0M0 glottic cancer: Japan Clinical Oncology Group Study (JCOG0701). Ann Oncol 29(4): 992-997, 2018. PMID: 29401241. DOI: 10.1093/annonc/mdy036

14 Edge SB and American Joint Committee on Cancer: AJCC Cancer Staging Manual. Seventh Edition. New York; London, Springer, 2010.

15 National Cancer Institute: National Cancer Institute Common Terminology Criteria for Adverse Events v4.0: June 14: 1-80, 2010 Available at: https://ctep.cancer.gov/protocolDevelopment/ electronic_applications/ctc.htm\#ctc_40 [Last accessed on 24th May 2020]

16 Kanda Y: Investigation of the freely available easy-to-use software 'EZR' for medical statistics. Bone Marrow Transplant 48(3): 452-458, 2013. PMID: 23208313. DOI: 10.1038/ bmt.2012.244

17 Le Q-TX, Fu KK, Kroll S, Ryu JK, Quivey JM, Meyler TS, Krieg RM and Phillips TL: Influence of fraction size, total dose, and overall time on local control of T1-T2 glottic carcinoma. Int J Radiat Oncol 39(1): 115-126, 1997. PMID: 9300746. DOI: 10.1016/s0360-3016(97)00284-8

18 Fein DA, Lee WR, Hanlon AL, Ridge JA, Curran WJ and Coia LR: Do overall treatment time, field size, and treatment energy influence local control of T1-T2 squamous cell carcinomas of the glottic larynx? Int J Radiat Oncol 34(4): 823-831, 1996. PMID: 8598359. DOI: 10.1016/0360-3016(95)02205-8

19 Withers HR, Taylor JMG and Maciejewski B: The hazard of accelerated tumor clonogen repopulation during radiotherapy. Acta Oncol 27(2): 131-146, 1988. PMID: 3390344. DOI: $10.3109 / 02841868809090333$
20 Garden AS, Forster K, Wong P-F, Morrison WH, Schechter NR and Ang KK: Results of radiotherapy for T2NO glottic carcinoma: does the "2" stand for twice-daily treatment? Int J Radiat Oncol 55(2): 322-328, 2003. PMID: 12527044. DOI: 10.1016/s0360-3016(02)03938-x

21 Okazaki E, Matsushita N, Tashiro M, Shimatani Y, Ishii K, Hosono M, Oishi M, Teranishi Y, Iguchi H and Miki Y: Efficacy and toxicity profiles of two chemoradiotherapies for stage II laryngeal cancer - a comparison between late course accelerated hyperfractionation (LCAHF) and conventional fractionation (CF). Acta Otolaryngol 137(8): 883-887, 2017. PMID: 28301268. DOI: $10.1080 / 00016489.2017 .1293295$

22 Trotti A, Zhang Q, Bentzen SM, Emami B, Hammond ME, Jones CU, Morrison WH, Sagar SM, Ridge JA, Fu KK and Ang KK: Randomized trial of hyperfractionation versus conventional fractionation in T2 squamous cell carcinoma of the vocal cord (RTOG 9512). Int J Radiat Oncol Biol Phys 89(5): 958-963, 2014. PMID: 25035199. DOI: 10.1016/j.ijrobp.2014.04.041

23 Bledsoe TJ, Park HS, Stahl JM, Yarbrough WG, Burtness BA, Decker RH and Husain ZA: Hypofractionated radiotherapy for patients with early-stage glottic cancer: Patterns of care and survival. JNCI J Natl Cancer Inst 109(10): 843-854, 2017. PMID: 28521361. DOI: 10.1093/jnci/djx042

24 Moore A, Den RB, Popovtzer A, Goldvaser H, Gordon N and Goldstein DA: Fractionation scheme and treatment planning method for early glottic cancer in the United States: Economic impact of different medical decisions. Head Neck, 2020. PMID: 31976607. DOI: $10.1002 /$ hed.26082

Received May 29, 2020

Revised June 20, 2020

Accepted June 24, 2020 